mentation of quality- and systemsrelated initiatives. Hospitalists have been slow to pursue substantial inquiry into discovery related to the common inpatient diseases they see or to lead multicenter trials of new diagnostic or therapeutic approaches. This deficiency limits hospitalists' credibility in academia and the advancement of the field.

Although we continue to believe that the hospitalist model is the best guarantor of high-quality, efficient inpatient care, it's clear that today's pressures require innovative approaches around this core. In addition to following patients in post-acute care facilities, another modified approach is to have a subgroup of hospitalists function as "comprehensivist" physicians who care for a small panel of the highest-risk, most frequently admitted outpatients and remain involved when hospitalization is required. This model aims to blend the advantages of the hospitalist model for the vast majority ( $>95 \%)$ of inpatients with the potential advantages of continuity for a small group of patients who are admitted repeatedly.

Hospitalist programs are innovating in other ways as well. Many are developing early-warning protocols in which electronic health record data are used to identify patients who are at risk for problems such as sepsis or falls. Others are implementing bedside ultrasonography for procedures and diagnosis, pioneering methods of making rounds more patientand family-centric, implementing unit-based leadership teams, or applying process-improvement approaches such as the Toyota Production System to inpatient care.

Many academic programs are also experimenting with new ways of reconnecting specialists and scientists with trainees. Some have begun offering focused basicscience training to hospitalists, others have developed molecular medicine consult services, and still others have instituted dual attending programs, with a consultative teaching specialist joining a more hands-on teaching hospitalist. Such innovations are welcome and should be studied. In fact, the field's greatest risk may well be complacency - failing to embrace the kinds of transformation and disruption that led to its birth, or being slow to address the inevitable side effects of even the best innovation.

When we described the hospitalist concept 20 years ago, we argued that it would become an important part of the health care landscape. Yet we couldn't have predicted the growth and influ- ence it has achieved. Today, hospital medicine is a respected field whose greatest legacies may be improvement of care and efficiency, injection of systems thinking into physician practice, and the vivid demonstration of our health care system's capacity for massive change under the right conditions.

Disclosure forms provided by the authors are available at NEJM.org.

From the Department of Medicine, University of California, San Francisco, San Francisco (R.M.W.); and the College of Physicians and Surgeons, Columbia University, New York (L.G.).

This article was published on August 10, 2016, at NEJM.org.

1. Wachter RM, Goldman L. The emerging role of "hospitalists" in the American health care system. N Engl J Med 1996;335:514-7.

2. Wachter RM, Katz P, Showstack J, Bindman AB, Goldman L. Reorganizing an academic medical service: impact on cost, quality, patient satisfaction, and education. JAMA 1998;279:1560-5.

3. Auerbach $\mathrm{AD}$, Wachter RM, Katz $\mathrm{P}$, Showstack J, Baron RB, Goldman L. Implementation of a voluntary hospitalist service at a community teaching hospital: improved clinical efficiency and patient outcomes. Ann Intern Med 2002;137:859-65.

4. The core competencies in hospital medicine: a framework for curriculum development by the Society of Hospital Medicine. J Hosp Med 2006;1:Suppl 1:2-95.

5. Auerbach $\mathrm{AD}$, Wachter RM, Cheng HQ, et al. Comanagement of surgical patients between neurosurgeons and hospitalists. Arch Intern Med 2010;170:2004-10.

DOI: 10.1056/NEJMp1607958

Copyright (c) 2016 Massachusetts Medical Society.

\title{
Hospitalists and the Decline of Comprehensive Care
}

\author{
Richard Gunderman, M.D., Ph.D.
}

M edical specialization dates back at least to the time of Galen. For most of medicine's history, however, the boundaries of medical fields have been based on factors such as patient age (pediatrics and geriatrics), ana- tomical and physiological systems (ophthalmology and gastroenterology), and the physician's toolset (radiology and surgery). Hospital medicine, by contrast, is defined by the location in which care is delivered. Whether such delineation is a good or bad sign for physicians, patients, hospitals, and society hinges on how we understand the interests and aspirations of each of these groups.

The hospitalist model has provided such putative benefits as 
reductions in length of stay, cost of hospitalization, and readmission rates - but these metrics are all defined by the boundaries of the hospital. What we don't yet know sufficiently well is the impact of the rise of hospital medicine on overall health status, total costs, and the well-being of patients and physicians. The increasing number of hospitalists cannot, in and of itself, be taken as conclusive evidence of benefit. Such increases can be driven by a variety of perverse incentives, such as low payment rates for primary care that place a premium on maximizing the number of patients a physician sees in a day and therefore militate against taking the extra time required to see inpatients.

In fact, increasing reliance on hospitalists entails a number of risks and costs for everyone involved in the health care system - most critically, for the patients that system is meant to serve. As the number of physicians caring for a patient increases, the depth of the relationship between patient and physician tends to diminish - a phenomenon of particular concern to those who regard the patient-physician relationship as the core of good medical care.

Practically speaking, increasing the number of physicians involved in a patient's care creates opportunities for miscommunication and discoordination, particularly at admission and discharge. Gaps between community physicians and hospitalists may result in failures to follow up on test results and treatment recommendations. ${ }^{1}$ Moreover, the acute care focus of hospital medicine may not match the need of many patients for effective disease prevention and health promotion. Studies are under way to see whether these pitfalls can be miti- gated, but I suspect the inherent tensions will remain fundamentally irresolvable.

From the patient's point of view, it can be highly disconcerting to discover that the physician who knows you best will not even see you at your moment of greatest need - when you are in the hospital, facing serious illness or injury. ${ }^{2}$ Who is better equipped to abide by an incapacitated patient's preferences or offer counseling on end-of-life care: a physician with whom the patient is well acquainted or one the patient has only just met? The patientphysician relationship is built largely on trust, and levels of trust are usually lower among strangers.

The hospitalist model also carries risks and costs for physicians. As community physicians, for their part, participate less frequently in the care of hospitalized patients, their knowledge and skills in hospital care may decline, and they may play a shrinking role in hospital-based education, as both teachers and learners. Over time, it's likely to become increasingly difficult for community physicians to really mean it when they promise patients to always be there for them - a limitation that may, in turn, erode the physician's professional fulfillment.

Meanwhile, hospitalists face a parallel narrowing of their comfort range. As members of a young field, many hospitalists have relatively little experience with outpatient medicine, a deficit that's exacerbated by hospitalonly practice. Physicians who never see outpatients are at a disadvantage in understanding patients' lives outside the hospital. Over time, hospitalists may become progressively less accountable to nonhospitalized patients and their communities, ultimately becoming less effective advocates for comprehensive medical care.

More broadly, the profession of medicine stands to suffer. As patient care becomes increasingly fragmented, many physicians find it more and more difficult to provide truly integrated care. Physicians whose practices rest on a clear separation between inpatient and outpatient care or manifest a shift-work mentality are more likely to respond to requests from patients and colleagues with, "Sorry, but that's not in my job description." Such practice models may make physicians' lives easier, but they may also reduce professional fulfillment and promote burnout.

At the same time, the physician's lounge, once an important site of knowledge sharing and professional collegiality, may become depopulated. Exclusively inpatient and outpatient physicians see each other less frequently, and medical students and residents have fewer role models who provide comprehensive care. In effect, the mounting walls of the hospital constitute an increasingly impermeable barrier between the members of the profession.

The very term "hospitalist" seems problematic. If we call some physicians hospitalists, should we call others "clinicists" or "officists"? Similarly, the move toward shift work may open the door to "matinists" and "nocturnists." Using a misnomer such as "hospitalist" to mean acute care medicine may seem harmless, but calling things by the wrong names is often the first step toward becoming confused about them - a particularly hazardous state of affairs for a profession facing an era of great flux.

A high percentage of hospitalists are employed by hospitals or 
work at only a single hospital, which can shift loyalty away from patients and the profession and toward the hospital. Some physicians may be captured by the hospital, whose incentives to increase market share and profits are not always well aligned with the best interests of patients and communities. For example, hospital marketing may encourage patients to suppose that their relationship with the hospital is more important than their relationship with any particular physician.

And yet even hospitals suffer in some ways from the hospitalist model. As community physicians relinquish their hospital privileges, the number of physicians on hospital medical staffs tends to decline. Fewer and fewer physicians in the community ever set foot in the hospital, let alone participate in its decision making. As a result, hospital leaders can become less informed and engaged with the needs of their community. In settings where community physicians have functioned as effective advocates, the loss of their voice can widen the gap between hospital policies and community needs.

The reality is that medicine can be practiced without hospitals, but hospitals cannot function without physicians. In wartorn parts of the world today, for example, physicians are caring for seriously ill and injured patients and even performing complex surgeries in outpatient settings. ${ }^{4}$ Although this state of affairs is undesirable, it's also a powerful reminder of the real sine qua non of medical care. A good hospital is a great boon to patient care, but the hospital itself is ultimately a tool - to be sure, a large, complex, expensive tool - without which patients can still be given care.

To position the hospital at medicine's center is to create an unbalanced system, one that will continually jar both patients and the health professionals who care for them. The true core of good medicine is not an institution but a relationship - a relationship between two human beings. And the better those two human beings know one another, the greater the potential that their relationship will prove effective and fulfilling for both. Models of medicine that ensconce physicians more deeply in spatial and temporal silos only make the prospects for such relationships even dimmer.

Disclosure forms provided by the author are available at NEJM.org.

From Indiana University School of Medicine, Indianapolis.

This article was published on August 10, 2016, at NEJM.org.

1. Pham HH, Grossman JM, Cohen G, Bodenheimer T. Hospitalists and care transitions: the divorce of inpatient and outpatient care. Health Aff (Millwood) 2008;27: 1315-27.

2. Meltzer D. Hospitalists and the doctorpatient relationship. J Legal Stud 2001;30: 589-606.

3. Bryant DC. Hospitalists and 'officists' preparing for the future of general internal medicine. J Gen Intern Med 1999;14:182-5.

4. Taub B. The shadow doctors: the underground race to spread medical knowledge as the Syrian regime erases it. The New Yorker. June 27, 2016 (http://www.newyorker.com/ magazine/2016/06/27/syrias-war-on-doctors).

DOI: 10.1056/NEJMp1608289

Copyright (c) 2016 Massachusetts Medical Society.

\title{
HISTORY OF CLINICAL TRIALS
}

\section{Clinical Trials, Healthy Controls, and the Birth of the IRB}

\author{
Laura Stark, Ph.D., and Jeremy A. Greene, M.D., Ph.D.
}

he U.S. Office for Human
Research Protections (OHRP)
is revising the Common Rule that
guides research involving human
subjects - the first substantial
overhaul of clinical research regu-
lation in 40 years. In 2011, when
the OHRP announced its plan to
revise the regulations, it described
the current system of review by
local institutional review boards
(IRBs) as burdensome for multi-
site studies, such as collaborative clinical trials, and as a force that "can significantly delay the initiation of research projects." The revisions will have global repercussions. In determining how best to fix the Common Rule, it is important to understand how our current local review system was designed to address specific problems in the 1950s, when randomized clinical trials were first emerging.

The local IRB review model stems from the practices that the National Institutes of Health (NIH) created for its research hospital, known as the Clinical Center, in Bethesda, Maryland. NIH scientists and lawyers created the system to manage a new kind of human subject - the "normal control" - for clinical studies that were far smaller than today's randomized, controlled trials (RCTs). Efforts to recruit healthy volunteers for medical research 